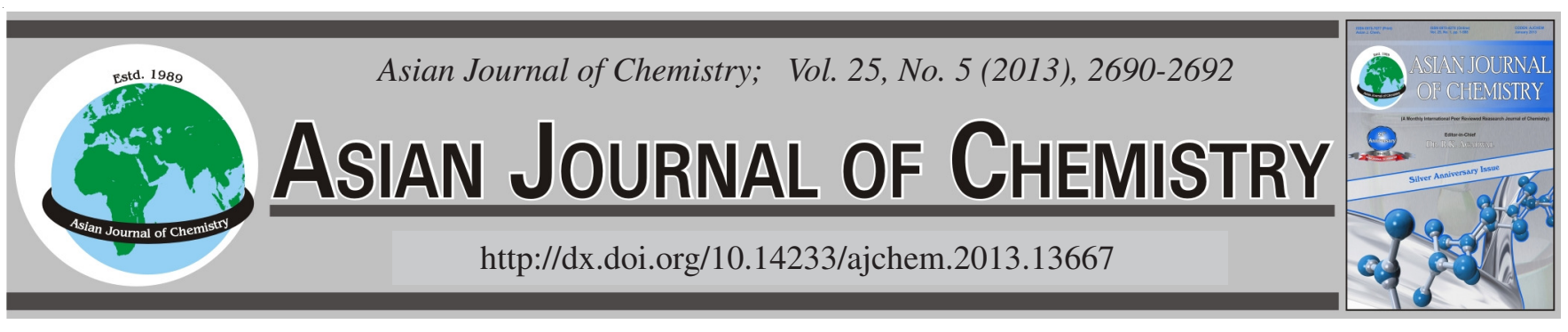

\title{
Cationic Polymerization of 1,3-Pentadiene in Presence of $\mathrm{AlCl}_{3} / \mathrm{SbCl}_{3}$
}

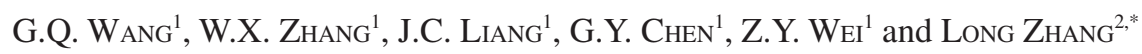

${ }^{1}$ College of Automotive Engineering, Dalian Science and Technology University, Dalian 116024, P.R. China

${ }^{2}$ School of Chemical Engineering, Changchun University of Technology, Changchun 130012, P.R. China

*Corresponding author: E-mail: zhanglongzhl@163.com

(Received: 29 February 2012;

Accepted: 19 November 2012)

AJC-12430

The cationic polymerization of 1,3-pentadiene using $\mathrm{AlCl}_{3} / \mathrm{SbCl}_{3}$ binary catalyst mainly carried out at various $\mathrm{SbCl}_{3}$ concentrations. With an increase in the $\mathrm{SbCl}_{3}$ concentration, the molecular weight decreased and molecular mass distribution of the polymer widened, that is consistent with $\beta$-pinene. It is shown that the degree of unsaturation of poly(1,3-pentadiene) are almost independent of the $\mathrm{SbCl}_{3} \mathrm{concen}^{-}$ trations.

Key Words: Cationic polymerization, 1,3-Pentadiene.

\section{INTRODUCTION}

1,3-Pentadiene (PD)-based polymers are produced through cationic polymerization are commonly synthesized in the presence of various Lewis acids ${ }^{1,2}$. These Lewis acids (e.g., aluminum chloride, titanium chloride) are the high activity and relatively low cost.

It is found that the addition of $\mathrm{SbCl}_{3}$ to aluminum halide catalysts like $\mathrm{AlCl}_{3}$ and $\mathrm{AlBr}_{3}$ accelerates the polymerization of $\alpha$-pinene $\mathrm{p}^{3-5}$. In the cationic polymerization of $\alpha$-pinene, with an increase in the $\mathrm{SbCl}_{3}$ concentration, the molecular weight of the polymer increased.However,in the cationic polymerization of $\beta$-pinene, with an increase in the $\mathrm{SbCl}_{3}$ concentration, the molecular weight decreased.

In this paper,we reported the cationic polymerization of 1,3-pentadiene under the action of $\mathrm{AlC}_{3} / \mathrm{SbCl}_{3}$. The influence of the $\mathrm{SbCl}_{3}$ concentration on the degree of unsaturation, the molecular weight and molecular weight distributions (MMDs) were investigated. The influences of temperature and solvents on the polymerization were also discussed.

Information on the cationic polymerization of 1,3-dienes in the presence of $\mathrm{AlCl}_{3} / \mathrm{SbCl}_{3}$ is available only in the literature $^{3-6}$, which describe the cationic polymerization of $\alpha$-pinene $e^{3-5}$ and $\beta$-pinene ${ }^{6}$. To our best of knowledge no data have been published on the cationic polymerization of 1,3-pentadiene in the presence of $\mathrm{AlCl}_{3} / \mathrm{SbCl}_{3}$.

\section{EXPERIMENTAL}

1,3-Pentadiene from Fluka was distilled over $\mathrm{CaH}_{2}$. Toluene (Aldrich) and cyclohexane (Aldrich) were distilled over $\mathrm{CaH}_{2}$ under reduced pressure. $\mathrm{AlCl}_{3}$ (Aldrich) was purified by subli- mation under argon atmosphere. $\mathrm{CH}_{2} \mathrm{Cl}_{2}$ (Aldrich) was distilled twice from $\mathrm{CaH}_{2}$ under an inert atmosphere. $\mathrm{SbC1}_{3}$ (Aldrich).

Polymerization: The polymerization was carried out in a three-neck-reactor equipped with Teflon magnet in a dry nitrogen atmosphere. $\mathrm{AlCl}_{3}, \mathrm{SbCl}_{3}$ and solvent were introduced into the three-neck-reactor. The polymerization was achieved by introduction of 1,3-pentadiene by syringe. After a given time, the polymerization was quenched by adding a small amount of methanol. An insoluble and a soluble fraction can be obtained. After filtration, the soluble fraction was washed with water and dried by evaporating the solvent and unreacted monomer. The insoluble fraction, i.e., the cross-linked polymer, was only dried under vacuum.

Measurements: ${ }^{1} \mathrm{H}$ spectra were recorded on a Bruker Avance $400 \mathrm{MHz}$ in deuterated chloroform or methylene chloride. The proton relative unsaturation loss per monomer unit $\left(\alpha_{\mathrm{H}}\right)$ calculated by ${ }^{1} \mathrm{H} \mathrm{NMR}\left(\mathrm{CDCl}_{3}\right)$ was defined as the difference between the theoretical unsaturation degree (equal to $25 \%$ of the total of protons, assuming negligible the ratio of 3,4-units $)$ and the experimental unsaturation degree $\left(\mathrm{d}_{\exp }=\right.$ integration of olefinic proton peaks/integration of aliphatic and olefinic proton peaks) divided by the theoretical unsaturation degree: $\alpha_{H}=\left(0.25-\mathrm{d}_{\text {exp }}\right) / 0.25$.

The molecular weight and the molecular weight distribution of the polymers were determined by size exclusion chromatography (SEC) in tetrahydrofuran on a chromatograph equipped with three polystyrene gel columns (PL gel). Number-average molecular weight and weight-average molecular weight were calculated on the basis of a polystyrene calibration. 


\section{RESULTS AND DISCUSSION}

Influence of temperature on 1,3-pentadiene polymerization in methylene chloride: In order to investigate the importance of temperature, the polymerizations were performed at various temperatures. Table- 1 shows the polymerization of 1,3-pentadiene with $\mathrm{AlCl}_{3} / \mathrm{SbCl}_{3}$ initiating system at various temperatures, which is slow at low temperature. The overall yield that increased with increasing temperature was low for run $1, c a .16 \%$. However, in order to obtain the best control of the polymerization, it is preferable to operate at low temperature. The polymerization temperature cannot be strongly decreased because the polymerization rate becomes too low. The proton relative unsaturation losses $\left(\alpha_{\mathrm{H}}\right)$ of the polymers were reported in Table-1. More cyclizations (Table-1) occurred at high temperature $\left(30^{\circ} \mathrm{C}\right)$ and the cyclizations contents little varied at low temperature $\left(-15\right.$ and $\left.0{ }^{\circ} \mathrm{C}\right)$. Indeed, the $\alpha_{\mathrm{H}}$ value varies from 0.649 to 0.652 .

\begin{tabular}{|c|c|c|c|c|c|}
\hline \multicolumn{6}{|c|}{$\begin{array}{c}\text { TABLE-1 } \\
\text { POLYMERIZATION OF 1,3-PENTADIENE WITH } \mathrm{AlCl}_{3} / \mathrm{SbCl}_{3} \\
\text { INITIATING SYSTEM AT VARIOUS TEMPERATURES }{ }^{\mathrm{a}}\end{array}$} \\
\hline \multirow[t]{2}{*}{ Run } & \multirow{2}{*}{$\begin{array}{l}\text { Temp. } \\
\left({ }^{\circ} \mathrm{C}\right)\end{array}$} & \multirow{2}{*}{$\begin{array}{l}\text { Yield } \\
(\%)\end{array}$} & \multicolumn{2}{|c|}{$\begin{array}{l}\text { Characteristics of the sol } \\
\text { fraction }\end{array}$} & \multirow{2}{*}{$\alpha_{\mathrm{H}}$} \\
\hline & & & $\overline{\mathrm{Mn}}(\mathrm{g} / \mathrm{mol})$ & $\overline{\mathrm{Mw}} / \overline{\mathrm{Mn}}$ & \\
\hline 1 & -15 & 15.7 & 2386 & 1.67 & 0.649 \\
\hline 2 & 0 & 53.1 & 3680 & 2.08 & 0.652 \\
\hline 3 & 15 & 100 & 4673 & 2.45 & 0.682 \\
\hline 4 & 30 & 100 & 5289 & 2.89 & 0.728 \\
\hline
\end{tabular}

Influence of mole ratios of $\mathrm{SbCl}_{3}$ to $\mathrm{AICl}_{3}$ on 1,3pentadiene polymerization in methylene chloride: The effects of the $\mathrm{SbCl}_{3}$ concentration were investigated (Table-2: $\mathrm{Sb} / \mathrm{Al}=0-1$ mol ratio). With increasing the $\mathrm{SbCl}_{3}$ concentration, the molecular weight decreased and molecular weight distributions increased. This was probably due to the suppression of polymerization by $\mathrm{SbCl}_{3}$, which might generate new initiating or/and propagating species with $\mathrm{AlCl}_{3}$. The active species was less reactive than only $\mathrm{AlCl}_{3}$. Indeed, the $\alpha_{\mathrm{H}}$ value varied from 0.695 to 0.682 . The presence of $\mathrm{SbCl}_{3}$ has reduced isomerization and cyclization content to different extents. However, the isomerization and cyclization content was very little affected by the $\mathrm{SbCl}_{3}$ concentration.

\begin{tabular}{|c|c|c|c|c|c|}
\hline \multicolumn{6}{|c|}{$\begin{array}{c}\text { TABLE-2 } \\
\text { POLYMERIZATION OF PD AT } \\
\text { MOLE RATIOS OF SbCl }{ }_{3} \text { TO }\end{array}$} \\
\hline \multirow[t]{2}{*}{ Run } & \multirow{2}{*}{$\begin{array}{l}{\left[\mathrm{SbCl}_{3}\right] /} \\
{\left[\mathrm{AlCl}_{3}\right]}\end{array}$} & \multirow{2}{*}{$\begin{array}{c}\text { Overall } \\
\text { yield (\%) }\end{array}$} & \multicolumn{2}{|c|}{$\begin{array}{c}\text { Characteristics of the sol } \\
\text { fraction }\end{array}$} & \multirow{2}{*}{$\alpha_{\mathrm{H}}$} \\
\hline & & & $\overline{\mathrm{Mn}}(\mathrm{g} / \mathrm{mol})$ & $\overline{\mathrm{Mw}} / \overline{\mathrm{Mn}}$ & \\
\hline 1 & 0 & 100 & 7912 & 1.75 & 0.695 \\
\hline 2 & 0.25 & 100 & 4674 & 2.02 & 0.693 \\
\hline 3 & 0.50 & 100 & 4624 & 2.45 & 0.682 \\
\hline 4 & 1 & 100 & 4625 & 2.45 & 0.682 \\
\hline
\end{tabular}

Influence of different solvents on 1,3-pentadiene polymerization: In order to investigate the importance of the solvent, the polymerizations were performed at various solvents (Table-3).

When polymerizations were realized in $n$-heptane, crosslinked polymer was produced. However, soluble polymer was scarcely produced. When polymerizations were realized in $\mathrm{CH}_{2} \mathrm{Cl}_{2}$ and toluene, the polymerization medium was almost homogeneous and nearly no cross-linked polymer was produced. The examination of the proton unsaturation loss of the polymers gave information on cyclization and isomerization reactions. Table-3 shows that the isomerization and cyclization content is greater in $\mathrm{CH}_{2} \mathrm{Cl}_{2}$ (higher $\alpha_{\mathrm{H}}$ ). This result was assigned to the formation of more dissociated active species. When the polymerization carried out in toluene, the SEC analysis showed a narrowing of the molar mass distribution and a decrease of the average number molar mass, which was mainly due to the occurrence of chain transfer reaction that led to the reduction of high molecular weight polymers. In the presence of toluene, for example:

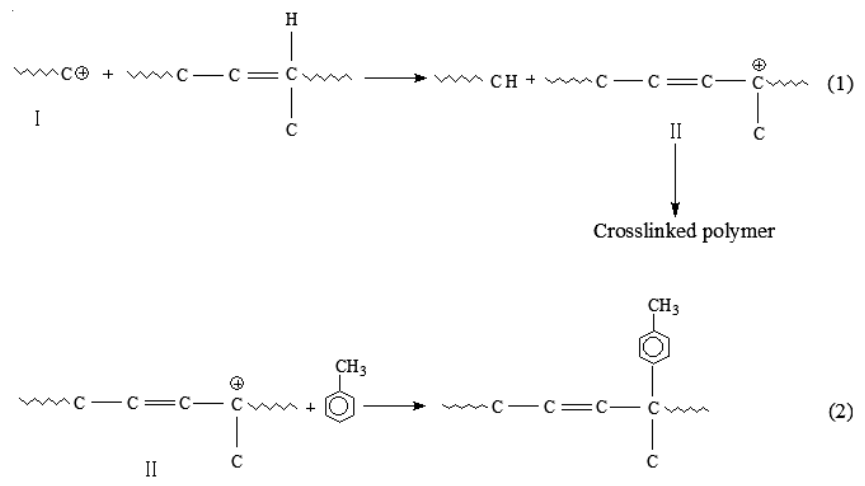

As the carbocation during a cationic polymerization can undergo a chain transfer to a aromatic group,the presence of aromatic compounds in the present polymerization could react with the carbocation II generated in eqn. 1 through a chain transfer reaction ${ }^{7}$. This result was confirmed by ${ }^{1} \mathrm{H}$ NMR after precipitation of the polymers in $\mathrm{CDCl}_{3}$ (Fig. 1). The analysis of the chemical structure showed the participation of toluene as a chain transfer agent $(\delta=2.31 \mathrm{ppm} ; \delta=7.07 \mathrm{ppm})$.

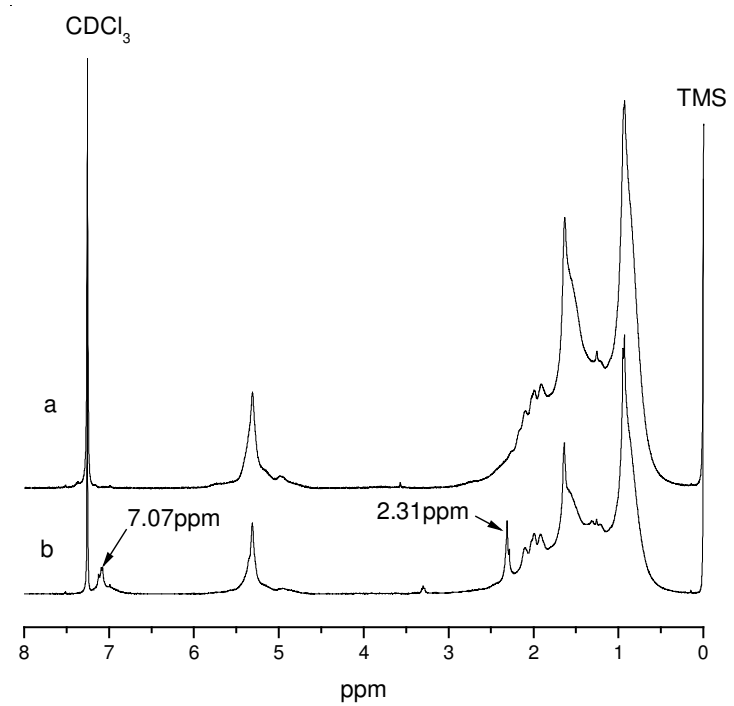

Fig. 1. ${ }^{1} \mathrm{H}$ NMR spectra of the polymers in $\mathrm{CH}_{2} \mathrm{Cl}_{2}$ and toluene, a: $\mathrm{CH}_{2} \mathrm{Cl}_{2}$; b: toluene 
TABLE-3

POLYMERIZATION OF 1,3-PENTADIENE AT DIFFERENT SOLVENTS ${ }^{c}$

\begin{tabular}{|c|c|c|c|c|c|c|}
\hline \multirow{2}{*}{ Run } & \multirow{2}{*}{ Solution } & \multirow{2}{*}{ Overall yield (\%) } & \multirow{2}{*}{$\begin{array}{c}\text { Gel fraction } \\
\text { content (wt \%) }\end{array}$} & \multicolumn{2}{|c|}{ Characteristics of the sol fraction } & \multirow[b]{2}{*}{$\alpha_{\mathrm{H}}$} \\
\hline & & & & $\overline{\overline{M n}}(\mathrm{~g} / \mathrm{mol})$ & $\overline{\mathrm{Mw}} / \overline{\mathrm{Mn}}$ & \\
\hline 1 & $n$-Heptane & 26 & 100 & - & - & - \\
\hline 3 & $\mathrm{CH}_{2} \mathrm{Cl}_{2}$ & 100 & 0 & 4675 & 2.45 & 0.682 \\
\hline
\end{tabular}

${ }^{\mathrm{c}}[\mathrm{PD}]=2.5 \mathrm{~mol} / \mathrm{L} ;\left[\mathrm{AlCl}_{3}\right]=4.6 \times 10^{-2} \mathrm{~mol} / \mathrm{L} ;\left[\mathrm{SbCl}_{3}\right]=2.3 \times 10^{-2} \mathrm{~mol} / \mathrm{L} ;$ time: $4 \mathrm{~h} ; \mathrm{T}=15^{\circ} \mathrm{C}$.

\section{REFERENCES}

1. F. Duchemin, V.B. Celton, H. Cheradame, C. Merienne and A. Macedo, Macromolecules, 31, 7627 (1998).

2. J. Santarella, E. Rousset, S. Randriamahefa, A. Macedo and H. Cheradame, Eur. Polym. J., 36, 2715 (2000).

3. T. Higashimura, J. Lu, M. Kamigaito, M. Sawamoto and Y.X. Deng, Makromol. Chem., 193, 2311 (1992).
4. T. Higashimura, J. Lu, M. Kamigaito, M. Sawamoto and Y.X. Deng, Makromol. Chem., 194, 3441 (1993).

5. T. Higashimura, J. Lu, M. Kamigaito, M. Sawamoto and Y.X. Deng, Makromol. Chem., 194, 3455 (1993).

6. J. Lu, M. Kamigaito, M. Sawamoto, T. Higashimura and Y.X. Deng, J. Appl. Polym. Sci., 61, 1011 (1996).

7. Y.X. Peng, J.L. Liu, L.R. Cun and H.S. Dai, Polym. Bull., 35, 393 (1995). 